\title{
Optimal hourly scheduling of hydro thermal systems integrating with renewable energy systems using differential evolution
}

\author{
V.HARIKA ${ }^{1}$, G.MADHAVI ${ }^{2}$ B.SONIA $^{3}$ \\ ${ }^{1}$ P V P Siddhartha Institute of Technology, India, vemulapalliaharika2312@pvpsiddhartha.ac.in \\ ${ }^{2}$ P V P Siddhartha Institute of Technology, India, gudavalli.madhavi@ pvpsiddhartha.ac.in \\ ${ }^{3}$ Vignan's Institute of Information technology, India, sonia.888b@ gmail.com
}

\begin{abstract}
Enormous wind liveliness and sun oriented power plants are broadly popularized and coordinated in existing electric power networks. The disproportion of wind speed over a brief era can incredibly influence transient age planning. Enormous extension sun based power plants are for the most part showcased and facilitated into existing electric power structures. Daylight based separation over a short period can essentially impact transient age. This paper watches out for this issue through an overhauled day ahead fleeting age booking of both warm and breeze imperative structures at different power invasion levels. Here one model of the breeze imperative power plant, sun based power plant is brought and facilitated into the made improvement model. The models acknowledge a static rate solar power cost. The perfect booking issue is lit up viably using differential turn of events. Diverse physical and operational objectives are fused. The results shows that breeze power assortment, and daylight based power are solidly impacting both warm and hydro power plants age arranging especially when need dispatch rules is normal.
\end{abstract}

Key words :Hydro thermal scheduling, wind energy, economic dispatch, differential evolution, wind penetration, solar energy

\section{INTRODUCTION}

Sustainable power sources (RES) are broadly popularized around the world. Numerous nations have set yearning intends to increment sunlight and wind based force entrance at an extensive level. The ideal is based on linear cost function model in which access wind powers are dissipated in bulk dummy resistors .In result, huge scope sun oriented force plants are associated and focused on existing force frameworks. A turning save from traditional warm force plants must be doled out to think about erratic sunlight based force varieties. Huge sun oriented confinement causes numerous effects on the long haul and momentary age booking which ought to be explored because of vulnerability related with sunlight based separation estimates. Here are the model is embraced to submit a sun based force plant. The model depends on a straight cost work model in which get to sunlight based forces are disseminated in mass sham resistors. The transient age booking (STGS) includes the explanation of an educated enhancement issue which requires productive streamlining agents. The cost of the fuel bends of warm plants are generally spoken to as nonlinear and non-raised with precluded working areas. Likewise, hydropower plants include a lot of physical and operational objectives including volumes and releases of fell supplies. Hence, regular inclination based techniques experience challenges because of the nonconvex plausible districts of the advancement issue. The dynamic programming approach is very ready to deal with such an issue without limitation prerequisites on cost work non-linearity or requirements [1]. Be that as it may, this methodology is very tedious which isn't fitting for brief timeframe planning issues of huge issues [2-3]. DE is one of the populace based metaheuristic stochastic developmental advancement procedures. Storn and Price previously awaited DE in 1995 [4] as a heuristic nonstop space capacities practically equivalent to other developmental calculations, the qualities are produced subjectively just because and further ages progress step by step through the relating of certain transformative administrators until a forestalling standard is obtained. DE is amazingly successful in taking care of enhancement issues that especially include non-smooth target capacities since it doesn't require subsidiary data. The DE calculation has been pragmatic to different fields of network advancement like ideal receptive force arranging in enormous scope appropriation frameworks [5], monetary dispatch issue [6], and so forth. Wang et al. introduced a method for tackling commercial dispatch with non-smooth and non-raised cost capacities utilizing crossbreed differential advancement [7]. Be that as it 
V.HARIKA et al., International Journal of Emerging Trends in Engineering Research, 8(10), October 2020,7600 - 7608

may, the exhibition of DE in understanding momentary monetary age booking of aqueous frameworks (STEGH) has not so far been accounted for by any gathering. This paper presents an effective and solid DE-based streamlining strategy for settling STEGH frameworks with the joining of elective vitality plants. The ethicalness of the arranged strategy is tried on two test plans including hydro and warm units at a given radiation. 24-hour day by day sun-powered figure information is considered from [12]. The power balance condition is considered though the framework misfortunes are ignored. The target work has been tackled utilizing method differential advancement [8]. The huge breeze power infiltration cause numerous effects on long haul and momentary age booking which ought to be examined because of vulnerability related with wind speed estimates. Here are the model is received to submit a breeze power plant. The model depends on direct cost work model in which access wind powers are dispersed in mass pretend resistors [13].

\section{PROBLEM FORMULATION}

The complete working expense of the aqueous sun based vitality frameworks for a 24-hour time arrangement is communicated as follows:

$$
\text { Cost } t_{\text {total }}=\sum_{\text {hour }=1}^{T}\left(\sum_{x=1}^{N_{\text {thermal }}} \operatorname{Cost} t_{m s}^{\text {hour }}+\sum_{y=1}^{N_{\text {solar }}} \operatorname{Cos} t_{n s o l}^{\text {hour }}\right)
$$

where Cost $_{\text {total }}$ cumulative cost of thermal and solar power generation

Cost $_{m s}$ cumulative cost of thermal power plant $m s$

Cost $_{n s o l}$ cumulative cost function of solar power plant $n$ sol

$T$ total time period

hourrepresents no.of hours, $N_{P}$ number of power plants

thermal, solar subscripts refer to thermal and solar power plants

In this wind turbine model, a typical $850 \mathrm{~kW}$ wind turbine capacity wind turbine is used to build the wind power plant [14]. According, the penetration-n level, the required number of wind turbines is calculated. The power curve of wind turbine is as shown in figure 1:

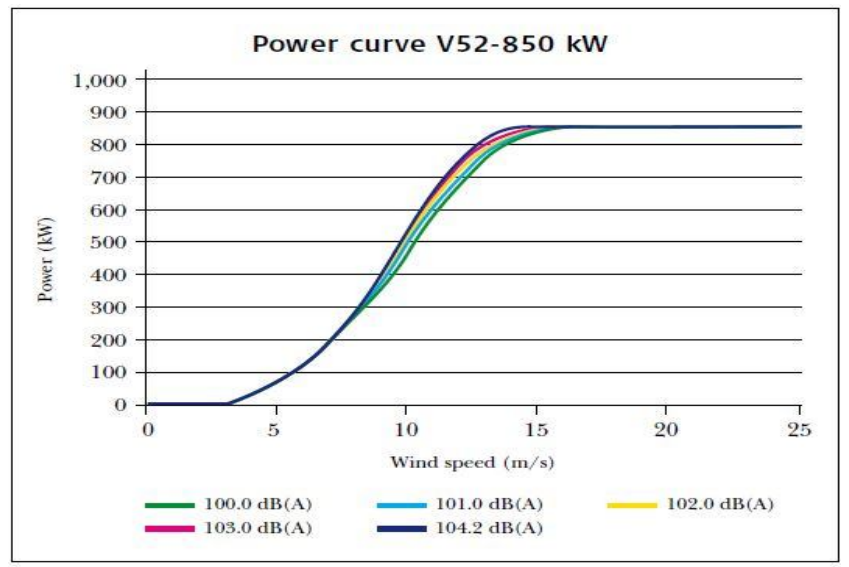

The figure above illustrates the power curves at different sound levels for the V52-850 kW turbine, which is equipped with OptiSpeed ${ }^{\text {w. }}$.

The wind energy power plant is stated as follows:

$$
\text { Cost }_{\text {wind }}=K_{\text {wind }} P_{\text {iwind }}
$$

Where $K_{\text {wind }}$ represents the cost of wind energy paid per $\mathrm{kW}, P_{i w i n d}$ refers to the output power of a wind farm. Due to uncertainness of the wind speed, $P_{i w i n d}$ is function in both the wind speed and the turbine characteristics. If a wind power plant enjoyed priority dispatch criteria, the factor $K_{\text {wind }}$ is assigned zero values. Subsequently, the wind power is communicated as follows:

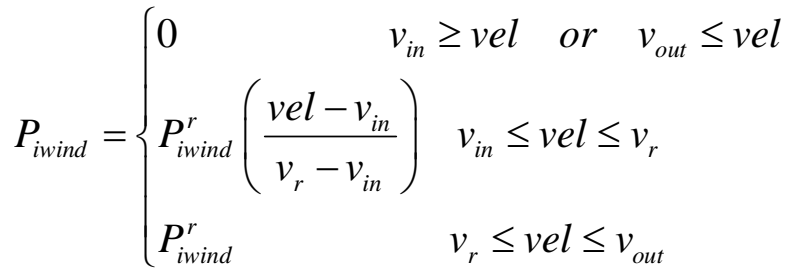

where

vel represents the wind speed,

rrefers the rated values of the turbine,

in refers to the cut-in speed, and

out refers to cut-out speed of the wind turbine

(vi) Wind speed limit

$W$ ind $v_{\text {in }} \leq$ Wind $v \leq W i n d v_{\text {out }}$

Where Windv is nominal wind speed Wind $v_{i n}$ start

up wind speed, Wind $v_{\text {out }}$ maximum wind speed

\subsection{Cost functions:}

The cost capacity of steam plants is communicated as a quadratic misfortune work with an extra two terms speaks to the non - convexity of the capacity as follows. 
V.HARIKA et al., International Journal of Emerging Trends in Engineering Research, 8(10), October 2020,7600 - 7608

$\operatorname{Cost}_{m s}=a_{m s}+b_{m s} P_{m s}+c_{m s} P_{m s}^{2}+\left|e_{m s} \sin \left(f_{m s}\left(P_{m s}^{m i n}-P_{m s}\right)\right)\right|$

Where for the $m^{\text {th }}$ thermal plant $a, b, c, e$, and $f$ are the fuel cost coefficients

The cost function of the solar power plant is expressed as

$\operatorname{Cost}_{\text {isol }}=\operatorname{Pow}_{P V C} *$ Kiso

Here the $K_{\text {iso }}$ is taken as the cost constant and it is taken as 3.5.The power output [9] from PV cell is expressed by

$\operatorname{Pow}_{P V C}=P_{\text {solr }}\left(\frac{G_{h t}^{2}}{G_{s t d} R_{C}}\right)$, for $0<G<R_{C}$

Pow $_{P V C}=P_{\text {solr }}\left(\frac{G_{h t}}{G_{s t d}}\right)$,for $G>R_{C}$

Where $P o w_{P V C}=$ power output from the solar cell

$G_{h t}=$ forecast solar radiation at hour ' $t$ '

Gstd = sun powered radiation in the standard condition set as $1000 \mathrm{~W} / \mathrm{m} 2$

$\mathrm{R}_{\mathrm{C}}=$ a certain radiation point set to $150 \mathrm{~W} / \mathrm{m} 2$

$P_{\text {solr }}=$ rated equivalent power output of the PV generator

Here $P_{\text {solr }}$ is taken as $150 \mathrm{MW}$ for both the test cases. The temperature of the PV cell is omitted. Power charge/discharge to/from the battery at hour $t$ is omitted.

The objective function is to reduce subject to a variety of constraints as follows:

(1) Active power balance

$\sum_{l=1}^{N_{s}} P_{s i t}+\sum_{m=1}^{N_{h}} P_{h j t}+\sum_{n=1}^{N_{s o l}} \operatorname{Pow}_{P V C k t}+\sum_{w=1}^{N_{w}} P_{w m t}-P_{D t}-P_{L t}=$

Where $P_{h j t}$ is the power generation of $m^{\text {th }}$ hydro generating unit at time interval $\mathrm{t}$,

Pow $w_{P V k t}$ is the solar power generation of $n^{\text {th }}$ power plant at time interval $\mathrm{t}$,

where $P_{w m t}$ is the power generation of $w^{\text {th }}$ wind power generating unit at time interval $t$,
$P_{D t}$ is power demand at time $t$ and $P_{L t}$ is total transmission loss at a particular time interval.

In this work, the power misfortune isn't reflected in straightforwardness. Be that as it may, it might be dictated by utilizing the B-misfortune framework straightforwardly. The hydropower age is an element of water release extent and repository stacking volume, which can be depicted by the accompanying condition as follows:

$P_{h j t}=C_{1 j} V_{o l} l_{h j t}^{2}+C_{2 j} Q_{h j t}^{2}+C_{3 j} V_{o l} l_{h j t} Q_{h j t}+C_{4 j} V_{o l} l_{h j t}+C_{5 j} Q_{h j t}+C_{6 j}$ (9)

Where $C_{1 j}, C_{2 j}, C_{3 j}, C_{4 j}, C_{5 j}$ and $C_{6 j}$ are power generation coefficients of $j^{\text {th }}$ hydro generating unit,

Vhjt is the capacity volume of jth repository at time $t$ and Qhjt is water release pace of jth store at time span $t$.

(2) Power generation limit

$P_{s i}^{\min } \leq P_{s i t} \leq P_{s i}^{\max }$

$P_{h j}^{\min } \leq P_{h j t} \leq P_{h j}^{\max }$

Where $P_{s i}{ }^{\min }$ and $P_{s i}{ }^{\max }$ are the lowest and highest power generation by $i^{\text {th }}$ thermal generating unit,

$P_{h j}^{\text {min }}$ and $P_{h j}^{\text {min }}$ are the lowest and highest power generation by ${ }^{\text {th }}$ hydro generating unit respectively.

(3) Water dynamic balance

$V o l_{h j t}=V o l_{h j, t-1}+I_{h j t}-Q_{h j t}-S_{h j t}+\sum_{m=1}^{R_{u j}}\left(Q_{h m, t-\tau_{m j}}+S_{h m, t-\tau_{m j}}\right)$

Where $I_{h j t}$ is natural inflow of $j^{\text {th }}$ hydro reservoir at time interval $t$,

$S_{h j t}$ is the spillage discharge rate of $j^{\text {th }}$ hydro generating unit at time interval $t$,

Q- $\tau_{m}$ is the water transport delay from reservoir $m$ to $j$ and $R_{u j}$ is the number of upstream hydro generating plants immediately above the $j^{\text {th }}$ reservoir.

(4) Reservoir storage volume limit

$V_{h j}^{\min } \leq V o l_{h j t} \leq V_{h j}^{\max }$

Where $V_{h j}^{\min }, V_{h j}^{\max }$ are the lowest and highest storage volume of $j^{\text {th }}$ reservoir. 
(5) Water discharge rate limit

$Q_{h j}^{\min } \leq Q_{h j t} \leq Q_{h j}^{\max }$

Where $Q_{h j}{ }^{\min }$ and $Q_{h j}{ }^{\max }$ are the lowest and highest water discharge rate of $j^{\text {th }}$ reservoir respectively.

The requirement of the function of the problem described is as follows,

$$
\text { M inCost } t_{\text {total }}=\sum_{\text {hour }=1}^{T}\left(\sum_{x=1}^{N_{\text {thermal }}} \operatorname{Cost} t_{m s}^{\text {hour }}+\sum_{y=1}^{N_{\text {solar }}} \operatorname{Cost} t_{\text {nsol }}^{\text {hour }}\right)
$$

\section{DIFFERENTIAL EVOLUTION}

Differential Evolution technique used here is described by the following steps.

\subsection{Initialization}

The streamlining movement in DE is yielded out with the accompanying four activities: initialization, mutation, crossover, and selection. The calculation starts with the formation of a populace vector P of size NPOP gathered of people that develop over a generation. Every individual $\mathrm{Xi}$ is a vector that encases the same number of components as the issue choice variable. Npop is the population size that is picked as the control parameter. In this manner,

$$
\begin{aligned}
& P^{(G)}=\left[X_{i}^{(G)}, \ldots \ldots, X_{N_{P O P}}^{(G)}\right] \\
& X_{i}^{(G)}=\left[X_{1, i}^{(G)}, \ldots \ldots, X_{D, i}^{(G)}\right]^{T}, \quad i=1, \ldots \ldots, N_{P O P}
\end{aligned}
$$

The preliminary population is chosen randomly in order to conceal the whole searching region evenly. Unvarying probability dissemination for all unsystematic variables is assumed in the following as

$$
X_{j, i}^{(0)}=X_{j}^{\mathrm{min}}+\sigma_{j}\left(X_{j}^{\mathrm{max}}-X_{j}^{\mathrm{min}}\right)
$$

where $i=1, N_{P O P}$ and $j=1, D$.

Here $D$ is the number of resolution or control variables, $X_{j}^{\text {min }}$ and $X_{j}^{\text {max }}$ are the inferior and superior limits of the $j^{t^{\text {th }}}$ decision variables and $\sigma \epsilon[0,1]$ is an evenly disseminated unsystematic number produced a new for each value of $j$. $X_{j, i}{ }^{\left({ }^{0)}\right.}$ is the ${ }^{\text {th }}$ parameter of the $i^{\text {th }}$ individual of the preliminary population.

\subsection{Mutation operation}

Vector difference is the crucial ingredient in the mutation operation. The mutation operator creates mutant vectors $\left(V_{i}\right)$ by disturbing a randomly selected vector $\left(X_{k}\right)$ with the dissimilarity of two other randomly selected vectors $\left(X_{k}\right.$ and $\left.X_{m}\right)$ according to:

$$
V_{i}^{(G)}=X_{k}^{(G)}+f_{m}\left(X_{l}^{(G)}-X_{m}^{(G)}\right)
$$

Where $X_{k}, X_{l}$ and $X_{m}$ are randomly chosen vectors $\epsilon$ [1. . $\left.\mathrm{N}_{\text {POP }}\right]$ and $k \neq l \neq m \neq i$. further, the indices are mutually distinct including the running index $i$. The mutation factor $f_{m}$ that lies within the vicinity of $[0,2]$ is a bound used to control the perturbation size in the mutation operator and to duck exploration sluggishness.

\subsection{Crossover operation}

So as to include further decent variety in the looking through the procedure, hybrid activity is performed. The hybrid activity creates preliminary vectors (Ui) by teaming up the parameter of the freak vectors with the objective vectors. For every freak vector, a file $q \epsilon[1, \ldots$, NPOP] is picked haphazardly utilizing a uniform appropriation and preliminary vectors are created by:

$U_{j, i}^{(G)} \begin{cases}V_{j, i}^{(G)} & \text { if } \quad \eta_{j} \leq C_{R} \quad \text { or } \quad j=q \\ X_{j, i}^{(G)} & \text { otherwise }\end{cases}$

Where $\mathrm{i}=1 \ldots$ NPOP and $\mathrm{j}=1 \ldots \mathrm{D} ; \mathrm{\eta}$ is a consistently dispersed irregular number inside $[0,1]$ produced another for each estimation of $\mathrm{j}$. The hybrid factor $\mathrm{CR} \epsilon[0,1]$ is a client picked parameter that controls the decent variety of the population. $\mathrm{Xj}, \mathrm{i}(\mathrm{G}), \mathrm{Vi}(\mathrm{G})$ and $\mathrm{Uj}, \mathrm{i}(\mathrm{G})$ are the $\mathrm{jth}$ parameter of the ith target vector, freak vector and preliminary vector at $\mathrm{G}$ generation, separately.

\subsection{Selection operation}

Better posterity is produced through choice activity. The wellness capacity of a posterity is assessed by contrasted and its parent. The parent position is reallocated by its posterity if the wellness of the posterity is progressed than that of its parent, while the parent is held for the people to come if the wellness of the posterity isn't superior to that of its parent. Therefore, in the event that $f$ signifies the cost (wellness) work under enhancement issue (minimization), at that point

$$
X_{i}^{(G+1)}= \begin{cases}U_{i}^{(G)} & \text { if } \quad f\left(U_{i}^{(G)}\right) \leq f\left(X_{i}^{(G)}\right) \\ X_{i}^{(G)} & \text { otherwise }\end{cases}
$$

The advancement procedure is rehashed for a few ages. This permits people to show signs of improvement wellness while investigating the arrangement space for ideal qualities. The mutation, crossover, and selection are rehashed iteratively until a client determined halting 
V.HARIKA et al., International Journal of Emerging Trends in Engineering Research, 8(10), October 2020,7600 - 7608

measure, ordinarily; the most extreme number of generations permitted is met. Keeping all these in thought the DE strategy has been applied to explain the present moment aqueous planning issue.

\section{RESULTS AND DISCUSSION}

In this paper, cascaded hydrothermal with two two multi-reservoirs systems were considered. The system is embraced of an equivalent thermal unit and four cascaded hydro units.

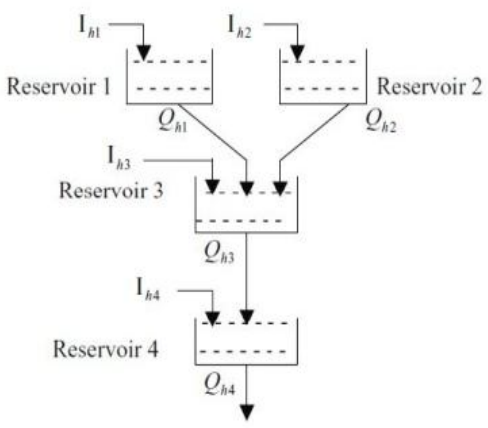

Figure 2: cascaded reservoir system of 4 hydro systems
The cascaded system used in this test case is represented by figure-1.

Test system 1 consists of 4 hydro one thermal systems. The forecast solar radiation data [14] are shown in appendix table A.1 the input characteristics of hydro and thermal system taken from [12]; load demand for 24 hours is given in appendix table A.2. Wind velocity for the test system is produced randomly and the output power is taken from the wind turbine model v52-850KW [14].The output power is calculated at different wind penetration levels.

The proposed test system consists of 1thermal, 4hydro, and 1 solar and 1 wind system with different penetration levels and is simulated on MATLAB R2013a with i3core processor and the results are taken after performing 10 operations to get accurate results.

The corresponding scheduled powers of hydrothermal system along with the solar and wind powers at different peneteration levels are tabulated below.

\begin{tabular}{|c|c|c|c|c|c|c|c|}
\hline \multicolumn{7}{|c|}{ Table-1:4 Hydro, 1 Thermal, 1Solar, 1 Wind systems with wind penetration 0 \% } \\
\hline Hour & Phy1(MW) & Phy2(MW) & Phy3(MW) & Phy4(MW) & Pvc(MW) & Pwin(MW) & Ps(MW) \\
\hline 1 & 52.9533 & 50.164 & 52.1096 & 200.0937 & 0 & 0 & 1014.7 \\
\hline 2 & 53.6471 & 67.1024 & 14.1832 & 187.7553 & 0 & 0 & 1067.3 \\
\hline 3 & 86.3239 & 71.4837 & 31.2332 & 209.6181 & 0 & 0 & 961.3 \\
\hline 4 & 98.2535 & 71.7334 & 0 & 176.6229 & 0 & 0 & 943.4 \\
\hline 5 & 64.8513 & 85.8826 & 38.4438 & 178.6595 & 0 & 0 & 922.2 \\
\hline 6 & 96.5851 & 82.8516 & 38 & 228.9299 & 0 & 0 & 963.6 \\
\hline 7 & 96.4712 & 55.994 & 28.7369 & 217.3719 & 12.321 & 0 & 1239.1 \\
\hline 8 & 66.321 & 56.476 & 38 & 255.9135 & 46.65 & 0 & 1536.6 \\
\hline 9 & 65.3396 & 76.93 & 37.8511 & 284.0687 & 56.25 & 0 & 1719.6 \\
\hline 10 & 52.0295 & 87.9303 & 0 & 266.6322 & 75.45 & 0 & 1838 \\
\hline 11 & 55.4285 & 80.2031 & 32.5772 & 249.37 & 92.55 & 0 & 1719.9 \\
\hline 12 & 92.2373 & 99.6143 & 7.8606 & 276.4883 & 102.9 & 0 & 1730.9 \\
\hline 13 & 52.9597 & 96.9819 & 42.5356 & 249.37 & 105.45 & 0 & 1682.7 \\
\hline 14 & 71.9019 & 78.9852 & 43.5836 & 249.37 & 110.4 & 0 & 1645.8 \\
\hline 15 & 56.1923 & 64.1227 & 45.928 & 249.231 & 87.9 & 0 & 1626.6 \\
\hline 16 & 102.2746 & 65.375 & 54.2931 & 249.37 & 63.75 & 0 & 1534.9 \\
\hline 17 & 78.8535 & 62.4943 & 38.6164 & 249.37 & 43.65 & 0 & 1657 \\
\hline 18 & 54.8696 & 91.8755 & 49.6729 & 286.8671 & 7.396 & 0 & 1649.3 \\
\hline 19 & 73.6739 & 68.6066 & 30.0808 & 246.6455 & 0 & 0 & 1821 \\
\hline 20 & 95.2819 & 79.7782 & 23.9613 & 272.1718 & 0 & 0 & 1808.8 \\
\hline 21 & 97.1746 & 56.1549 & 10.03 & 246.5948 & 0 & 0 & 1830 \\
\hline 22 & 83.5243 & 51.1748 & 37.5981 & 265.1404 & 0 & 0 & 1682.6 \\
\hline 23 & 72.7299 & 65.952 & 55.3638 & 232.3898 & 0 & 0 & 1423.6 \\
\hline 24 & 69.3385 & 42.6761 & 53.255 & 229.5512 & 0 & 0 & 1195.2 \\
\hline
\end{tabular}


V.HARIKA et al., International Journal of Emerging Trends in Engineering Research, 8(10), October 2020, 7600 - 7608

\begin{tabular}{|c|c|c|c|c|c|c|c|}
\hline \multicolumn{9}{|c|}{ Table 2: 4 Hydro, 1 Thermal, 1Solar, 1 Wind systems with wind penetration 2.5 \% } \\
\hline Hour & Phy1(MW) & Phy2(MW) & Phy3(MW) & Phy4(MW) & Pvc(MW) & Pwin(MW) & Ps(MW) \\
\hline 1 & 53.4212 & 50.164 & 52.0952 & 198.7662 & 0 & 58 & 906.5 \\
\hline 2 & 68.3859 & 70.0373 & 0 & 218.9883 & 0 & 50.6656 & 942.8 \\
\hline 3 & 98.7349 & 60.9092 & 39.9659 & 172.2515 & 0 & 43.1781 & 906.5 \\
\hline 4 & 96.6354 & 83.1231 & 27.3728 & 192.3269 & 0 & 58 & 833.2 \\
\hline 5 & 87.3358 & 55.504 & 0 & 177.2884 & 0 & 58 & 795.3 \\
\hline 6 & 62.4781 & 82.4158 & 34.3623 & 222.1269 & 0 & 58 & 869.8 \\
\hline 7 & 87.1175 & 55.994 & 38.6244 & 225.889 & 12.321 & 58 & 1090.9 \\
\hline 8 & 55.1194 & 59.3836 & 0 & 233.0932 & 46.65 & 58 & 1423.6 \\
\hline 9 & 94.0306 & 88.1437 & 0 & 268.7424 & 56.25 & 49.5949 & 1645.8 \\
\hline 10 & 54.995 & 91.2398 & 26.3318 & 294.5375 & 75.45 & 58 & 1689 \\
\hline 11 & 103.0547 & 79.6972 & 38.0062 & 249.37 & 92.55 & 58 & 1577.6 \\
\hline 12 & 105.263 & 91.0075 & 4.9886 & 303.0527 & 102.9 & 58 & 1608.7 \\
\hline 13 & 87.3563 & 82.7181 & 0 & 288.726 & 105.45 & 58 & 1572 \\
\hline 14 & 68.7143 & 59.504 & 0 & 249.37 & 110.4 & 58 & 1608.7 \\
\hline 15 & 86.0761 & 80.0422 & 38.5455 & 289.5295 & 87.9 & 48.356 & 1461.2 \\
\hline 16 & 102.6594 & 84.4578 & 44.7608 & 294.2717 & 63.75 & 58 & 1421.6 \\
\hline 17 & 104.7796 & 58.0744 & 44.2813 & 249.2981 & 43.65 & 58 & 1550.1 \\
\hline 18 & 91.6252 & 76.1342 & 49.5912 & 247.9277 & 7.396 & 58 & 1533.5 \\
\hline 19 & 69.2505 & 54.3779 & 29.0569 & 279.6795 & 0 & 51.0745 & 1719.1 \\
\hline 20 & 55.1018 & 53.4779 & 45.6849 & 237.1106 & 0 & 58 & 1719.7 \\
\hline 21 & 54.8512 & 47.5152 & 53.1794 & 234.6716 & 0 & 58 & 1719.3 \\
\hline 22 & 57.3298 & 82.2221 & 53.1572 & 238.1856 & 0 & 44.2657 & 1534.7 \\
\hline 23 & 54.9394 & 54.6897 & 55.964 & 267.3362 & 0 & 58 & 1313.1 \\
\hline 24 & 83.8546 & 74.729 & 58.6431 & 231.4048 & 0 & 49.8234 & 1091.2 \\
\hline
\end{tabular}

\begin{tabular}{|c|c|c|c|c|c|c|c|}
\hline \multicolumn{7}{|c|}{ Table 3: 4 Hydro, 1 Thermal, 1Solar, 1 Wind systems with wind penetration 5 \% } \\
\hline Hour & Phy1(MW) & Phy2(MW) & Phy3(MW) & Phy4(MW) & Pvc(MW) & Pwin(MW) & Ps(MW) \\
\hline 1 & 51.8008 & 50.0787 & 52.0952 & 200.0937 & 0 & 109.4464 & 906.5 \\
\hline 2 & 52.6287 & 59.3593 & 0 & 226.284 & 0 & 108.9224 & 942.8 \\
\hline 3 & 53.1293 & 77.917 & 0 & 210.6114 & 0 & 111.8207 & 906.5 \\
\hline 4 & 66.7893 & 88.039 & 16.3235 & 188.9432 & 0 & 96.7449 & 833.2 \\
\hline 5 & 97.3728 & 58.2741 & 8.0334 & 215.0479 & 0 & 116 & 795.3 \\
\hline 6 & 87.2823 & 92.6722 & 38 & 206.249 & 0 & 116 & 869.8 \\
\hline 7 & 85.4146 & 92.0718 & 36.1208 & 217.1389 & 12.321 & 116 & 1090.9 \\
\hline 8 & 62.7155 & 84.8678 & 38.4642 & 229.8484 & 46.65 & 113.8721 & 1423.6 \\
\hline 9 & 85.6016 & 64.0247 & 27.0412 & 245.3299 & 56.25 & 116 & 1645.8 \\
\hline 10 & 91.4248 & 66.9689 & 31.7461 & 249.37 & 75.45 & 116 & 1689 \\
\hline 11 & 74.0428 & 72.1313 & 39.6549 & 258.0252 & 92.55 & 116 & 1577.6 \\
\hline 12 & 86.858 & 89.5383 & 41.7832 & 264.1751 & 102.9 & 116 & 1608.7 \\
\hline 13 & 88.6002 & 63.5023 & 42.0512 & 242.3508 & 105.45 & 116 & 1572 \\
\hline 14 & 65.9233 & 58.9619 & 0 & 240.0489 & 110.4 & 116 & 1608.7 \\
\hline 15 & 78.6553 & 66.0289 & 54.1357 & 266.0518 & 87.9 & 116 & 1461.2 \\
\hline 16 & 90.249 & 57.2314 & 53.7848 & 267.4304 & 63.75 & 116 & 1421.6 \\
\hline 17 & 62.2314 & 57.6869 & 53.158 & 247.2122 & 43.65 & 116 & 1550.1 \\
\hline 18 & 70.4317 & 73.0961 & 51.0539 & 288.5692 & 7.396 & 116 & 1533.5 \\
\hline 19 & 54.9673 & 75.1796 & 23.3997 & 256.4442 & 0 & 110.8839 & 1719.1 \\
\hline 20 & 58.7511 & 77.358 & 50.7086 & 257.5238 & 0 & 116 & 1719.7 \\
\hline 21 & 83.6028 & 70.7449 & 12.574 & 237.8019 & 0 & 116 & 1719.3 \\
\hline 22 & 91.1191 & 55.2871 & 59.969 & 262.9577 & 0 & 116 & 1534.7 \\
\hline 23 & 85.4782 & 47.1038 & 48.5331 & 239.7691 & 0 & 116 & 1313.1 \\
\hline 24 & 70.8856 & 42.7 & 46.8582 & 231.2369 & 0 & 107.0868 & 1091.2 \\
\hline
\end{tabular}


V.HARIKA et al., International Journal of Emerging Trends in Engineering Research, 8(10), October 2020,7600 - 7608

\begin{tabular}{|c|c|c|c|c|c|c|c|}
\hline \multicolumn{7}{|c|}{ Table 4: 4 Hydro, 1 Thermal, 1Solar, 1 Wind systems with wind penetration 7.5 \% } \\
\hline Hour & Phy1(MW) & Phy2(MW) & Phy3(MW) & Phy4(MW) & Pvc(MW) & Pwin(MW) & Ps(MW) \\
\hline 1 & 52.9593 & 50.0499 & 52.6458 & 200.0937 & 0 & 174 & 840.3 \\
\hline 2 & 67.9415 & 51.1851 & 22.349 & 187.7553 & 0 & 155.1174 & 905.7 \\
\hline 3 & 54.0618 & 55.6988 & 0 & 173.7333 & 0 & 174 & 902.5 \\
\hline 4 & 98.5311 & 69.7452 & 38.4961 & 177.4733 & 0 & 174 & 731.8 \\
\hline 5 & 90.1074 & 55.4058 & 32.9569 & 175.4997 & 0 & 172.4667 & 763.6 \\
\hline 6 & 97.8057 & 55.8974 & 38.6536 & 195.9811 & 0 & 174 & 847.7 \\
\hline 7 & 78.6597 & 85.3938 & 38 & 241.5039 & 12.321 & 174 & 1020.1 \\
\hline 8 & 72.4304 & 90.0648 & 36.1301 & 272.0503 & 46.65 & 167.2309 & 1315.4 \\
\hline 9 & 92.0957 & 86.9988 & 0 & 246.981 & 56.25 & 174 & 1583.7 \\
\hline 10 & 88.1769 & 79.9878 & 5.8404 & 249.37 & 75.45 & 174 & 1647.2 \\
\hline 11 & 93.0801 & 90.6779 & 0 & 293.7786 & 92.55 & 160.1436 & 1499.8 \\
\hline 12 & 87.7684 & 60.4904 & 38.2294 & 255.1509 & 102.9 & 156.3219 & 1609.1 \\
\hline 13 & 66.2791 & 66.3581 & 0 & 288.1557 & 105.45 & 174 & 1529.8 \\
\hline 14 & 73.2838 & 60.6428 & 41.3081 & 249.37 & 110.4 & 150.631 & 1514.4 \\
\hline 15 & 72.8764 & 89.8158 & 35.3644 & 249.37 & 87.9 & 174 & 1420.7 \\
\hline 16 & 78.6264 & 69.103 & 40.3814 & 249.37 & 63.75 & 174 & 1394.8 \\
\hline 17 & 54.6684 & 78.3124 & 55.4256 & 272.9138 & 43.65 & 165.4609 & 1459.6 \\
\hline 18 & 99.6987 & 93.3158 & 55.7964 & 248.2007 & 7.396 & 174 & 1461.6 \\
\hline 19 & 54.9204 & 55.7338 & 54.1948 & 277.1427 & 0 & 174 & 1624 \\
\hline 20 & 69.9585 & 89.965 & 55.3377 & 244.4818 & 0 & 174 & 1646.3 \\
\hline 21 & 91.618 & 68.8509 & 44.0746 & 252.5326 & 0 & 174 & 1608.9 \\
\hline 22 & 72.4924 & 68.5095 & 42.2768 & 240.5151 & 0 & 160.448 & 1535.8 \\
\hline 23 & 86.5611 & 63.0448 & 52.4786 & 234.4474 & 0 & 174 & 1239.5 \\
\hline 24 & 55.02 & 61.4988 & 20.2523 & 229.4439 & 0 & 174 & 1049.8 \\
\hline
\end{tabular}


The total cost of generation when 1hydro, 4thermal, 1solar and 1 wind system is considered at different penetration level is tabulated in the table. By observing the cost of generation we can conclude that when there is no wind then the cost of generation is $914341.6588 \$$ and when the penetration level increases from $0 \%$ to $7.5 \%$ then the cost of generation is decreasing which will be equal to $809822.4564 \$$.

\begin{tabular}{|c|c|}
\hline \multicolumn{2}{|c|}{ Table 5 : cost at different penetartions } \\
\hline wind penetration $(\%)$ & Cost $(\$)$ \\
\hline 0 & 914341.6588 \\
\hline 2.5 & 875040.9795 \\
\hline 5 & 842410.6764 \\
\hline 7.5 & 809822.4564 \\
\hline
\end{tabular}

The corresponding cost curve and bar graph are shown in the figures.
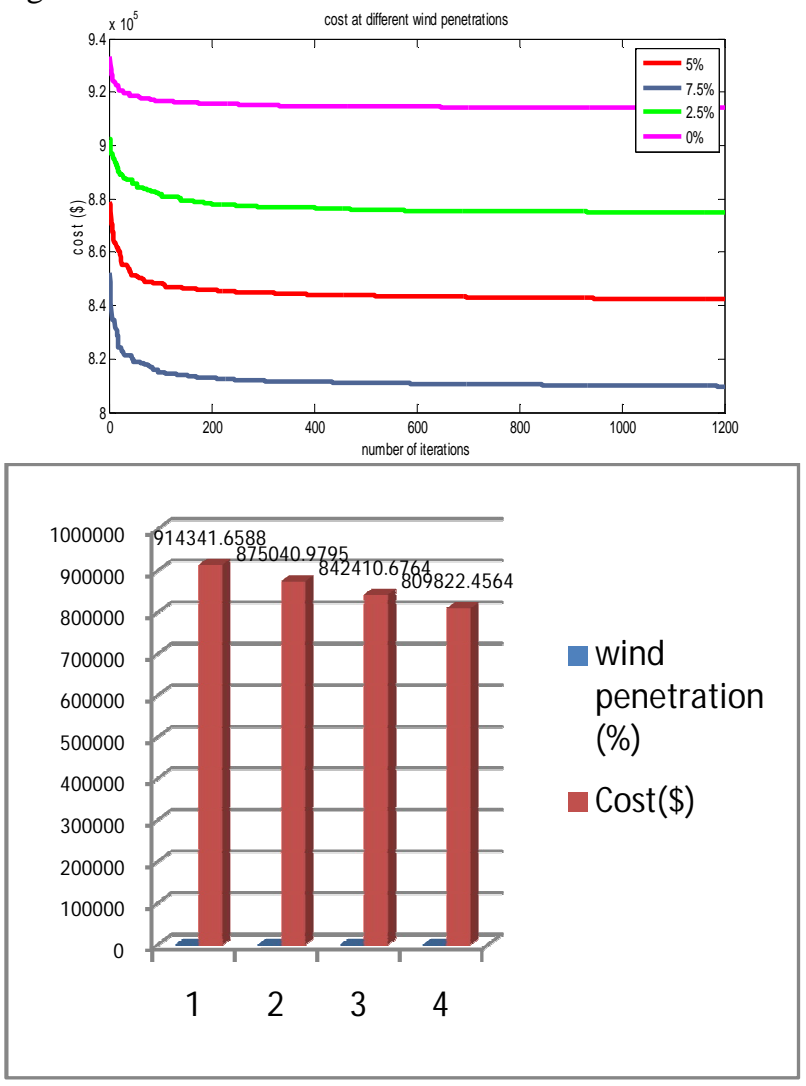

\section{CONCLUSION:}

With the enormous accessibility of sustainable wellsprings of vitality the working expense of the aqueous framework can be diminished and we can be less subject to nonrenewable wellsprings of vitality. In this paper we can discover ideal hourly scheduling of sun oriented, wind, hydro and thermal frameworks by utilizing differential advancement calculation. In this paper we can likewise presume that with various wind penetration levels the ideal expense of activity is shifted. Higher the infiltration level lesser the activity cost.

\section{REFERENCES:}

[1] A. J. Wood and B. F. Wollenberg, Power Generation Operation and Control, New York, NY: John Wiley \& Sons, Inc., 1996, pp. 39,517.

[2] F. Y.K. Takigawa, E. L. da Silva,E. C. Finardi,R. N. Rodrigues, "Solving the hydrothermal scheduling problem considering network constraints", Electric Power Systems Research, vol. 88, pp. 89- 97, 2012

[3] R. Baoss, F. Manzano-Agugliaro, F.G. Montoya, C. Gil, A. Alcayde, and J.Gméz, Optimization methods applied to renewable and sustainable energy: A review", Renewable and Sustainable Energy Reviews, vol. 15, no. 4, pp.1753-1766

[4] R. Storn, K. Price, Differential evolution: a simple and efficient adaptive scheme for global optimization over continuous spaces. Technical Report TR-95-012,Berkeley, USA: International Computer Science Institute, 1995

[5] C.-F. Changa, J.-J.Wong, J.-P.Chiou, C.-T.Su, Robust searching hybrid differential evolution method for optimal reactive power planning in large-scale distribution systems, Electr. Power Syst. Res. 77 (2007) 430-437.

[6] J.P. Chiou, Variable scalinghybriddifferential evolution for large-scale economic dispatch problems, Electr. Power Syst. Res. 77 (2007) 212-218.

[7] S.K.Wang, J.P. Chiou, C.W. Liu, Non-smooth/non-convex economic dispatch by a novel hybrid differential evolution algorithm, IET Gener. Transm.Distrib. 1 (5) (2007) 793-803.

[8] K. K. Mandal and N. Chakraborty, "Differential evolution technique based short-term economic generation scheduling of hydrothermal systems,'Elect. Power Syst. Res., vol. 78, no. 11, pp. 1972-1979, Nov.2008.

[9] Mousumi Basu1"Dynamic economic dispatch with demand- side management incorporating renewable energy sources and pumped hydroelectric energy storage", Electrical Engineering $\odot$ Springer-Verlag GmbH Germany, part of Springer Nature 2019.

[10] N. Sinha, R. Chakrabarti, and P. K. Chattopadhyay, "Fast evolutionary programming techniques for short-term hydrothermal scheduling,"IEEE Trans. Power Syst., vol. 18, no. 1, pp. 214-219, Feb. 2003

[11] M. Basu "An interactive fuzzy satisfying method based on evolutionary programming technique for multi objective short-term hydrothermal scheduling", Electric Power Systems Research, vol. 69, no. 2-3, pp. 277-285, May 2004.

[12] Liang R, Liao J (2007) A fuzzy-optimization approach for generation scheduling with wind and solar energy systems.IEEE Trans PWRS22 (4):1665-1674.

[13] J. Hetzer, D. C. Yu, and K. Bhattarai, "An Economic Dispatch Model

Incorporating Wind Power", IEEE Transactions on Energy Conversion, Vol.23, No. 2, pp. 603-611, June 2008

[14] Wind turbine data, V52-850 kW, avilable at" http://www.vestas.com 
V.HARIKA et al., International Journal of Emerging Trends in Engineering Research, 8(10), October 2020, 7600 - 7608

[15]B.Mohan, M.V.Ramesh, Melimi Ravi Kumar, T.Srinivasa Rao, P.Muthukumar, "Dual Axis Solar Tracking System with LDR", International journal of Emerging Trends in Engineering Research(IJETER), Volume8. No.8,August 2020

[16] Eunsung Oh" Rolling Based Energy Storage System Operation Strategies Considering wind power forecast Uncertainty", International journal of

Emerging Trends in Engineering research (IJETER), volume 7, No.11 November 2019, ISSN 2347-3983,

pages 708-714.

https://doi.org/10.30534/ijeter/2019/497112019.

[17] G.MADHAVI, V.HARIKA, "Optimal Hourly Scheduling Of Hydro Thermal Systems Integrating With Solar Power Systems Using Differential Evolution", International Journal of Scientific \& Technology Research Volume 9, Issue 06, June 2020, PP: 886-892, ISSN 2277-8616. 